\title{
DEVOCIONES Y SIGNIFICADOS QUE MIGRAN. EL SEÑOR DE LA EXPIRACIÓN DE COQUIMATLÁN, COLIMA $^{1}$
}

\author{
Silvia ORTIZ ECHANIZ \\ Instituto Nacional de Antropología e Historia (México) \\ sortiz.deas@inah.gob.mx
}

\section{Laura Elena CORONA DE LA PEÑA}

Instituto Nacional de Antropología e Historia (México)

laura_elena_corona@hotmail.com

\section{Leonardo VEGA FLORES}
Universidad Nacional Autónoma de México (México) famvefl@hotmail.com

\footnotetext{
1 Agradecemos profundamente a las maestras Mercedes y Socorro Ballesteros la valiosa información que nos proporcionaron, además de su hospitalidad, cordialidad y calidez. Igualmente agradecemos al sr. Jesús Rodríguez Ruiz, cronista de Coquimatlán y al sr. Pablo Ballesteros Silva, quienes nos proporcionaron testimonios muy importantes para este trabajo.
} 
Resumen: Se analizan algunos s-códigos de la devoción dedicada al Señor de la Expiración en Coquimatlán, Colima, México, y su importancia para la conservación del vínculo de los llamados «hijos ausentes» (emigrantes) con su comunidad de origen.

Abstract: We analyze some s-codes of Señor de la Expiracion (Sir of the Expiration) devotion in Coquimatlán, Colima, Mexico, and its importance for the conservation of the link between the so called «absent children» (emigrants) with their community of origin.

Palabras clave: Señor de la Expiración. México. Emigrantes. S-códigos.

Key Words: Expiration Sir. México. Emigrants. S-codes.

\section{INTRODUCCIÓN}

Como parte de la investigación que desarrollamos sobre el culto al Señor de la Expiración en Coquimatlán, Colima, en este texto nos proponemos analizar los s-códigos presentes en uno de sus aspectos más importantes de esta devoción: los vínculos que a través de ella se establecen entre los emigrantes a los Estados Unidos de Norteamérica y su lugar de origen. El culto al Señor de la Expiración es una de las principales expresiones de la identidad coquimatlense y en ella tienen importante participación los emigrantes conocidos como los «hijos ausentes». Nuestro análisis se enfoca específicamente a la construcción histórica de códigos comunicativos propios de esta devoción y en él se aplican las herramientas teórico-metodológicas de la antropología, la historia y la semiótica postestructural.

Tal como afirmamos en otro texto (Ortiz, 1995: 21 y 24), la comunidad de creencias, valores y prácticas religiosas refuerzan la seguridad participativa a través de códigos de representaciones asumidas, que a su vez permiten a las personas reelaborar estrategias para enfrentar situaciones cambiantes como las que impone la migración y de esta manera mantener los vínculos de los emigrantes con su población de origen ${ }^{2}$. Asimismo, hemos afirmado que la identidad se funda en un doble proceso de autorreconocimiento, a través del cual cada persona se adscribe a un grupo social y éste a su vez lo reconoce como integrante del mismo.

${ }^{2}$ Good (2005: 109) propone algo similar, pero en otro contexto, para el caso de los nahuas de Guerrero. 
En el caso que abordamos, las prácticas religiosas vinculadas inmemorialmente al ciclo agrícola se han reelaborado para responder a las circunstancias impuestas por la creciente migración internacional y, de esta manera, la población de Coquimatlán ha mantenido los vínculos con sus «hijos ausentes», quienes siguen participando en las distintas festividades, además de recibir al Señor de la Expiración en los Estados Unidos.

\section{LA DEVOCIÓN AL SEÑOR DE LA EXPIRACIÓN EN COQUIMATLÁN, COLIMA}

Coquimatlán es uno de los 10 municipios que componen el pequeño estado de Colima (Mapa n. ${ }^{\circ} 1$ ); su cabecera se llama también Coquimatlán y sus principales actividades económicas son la agricultura ${ }^{3}$ y la ganadería ${ }^{4}$; se trata de un municipio eminentemente católico en el que, según el censo de población del año 2000, el 96,64\% de las personas declararon pertenecer a esta religión, superando el $93 \%$ a nivel estatal y el $88 \%$ a nivel nacional ${ }^{5}$.

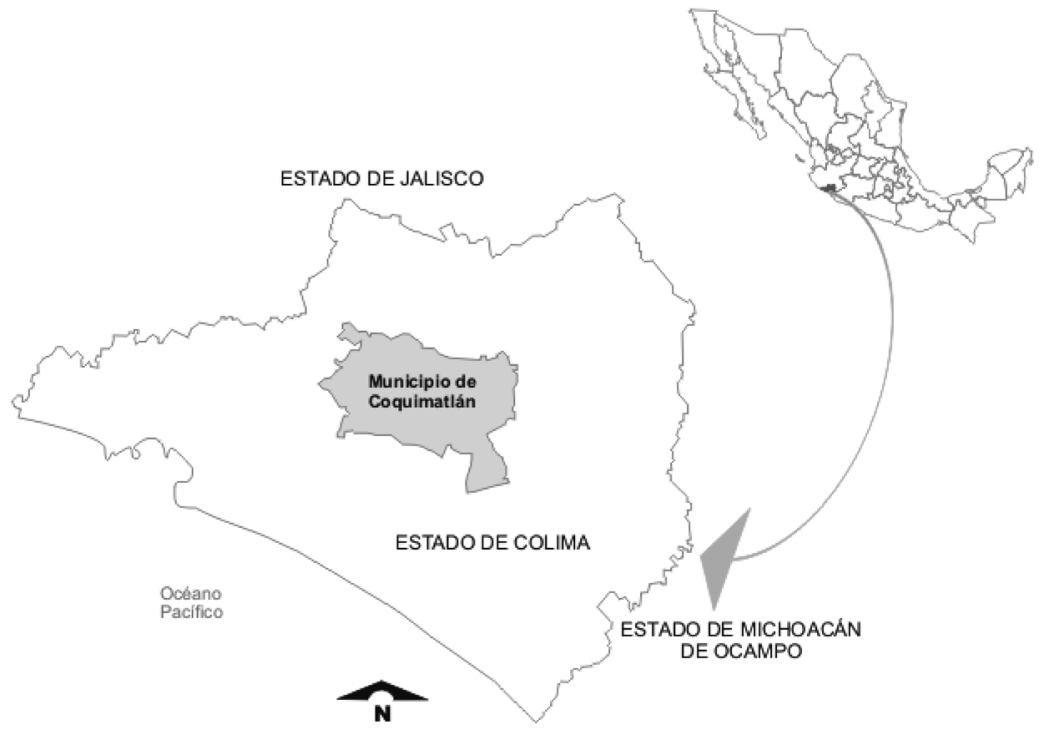

Mapa n. ${ }^{\circ}$ 1: El municipio de Coquimatlán, Colima.

\footnotetext{
${ }^{3}$ Los cultivos principales son maíz, limón, arroz, frutales y hortalizas.

${ }^{4}$ Principalmente de ganado bovino, porcino, caprino y caballar. También se crían aves.

5 Población de 5 años y más, INEGI, 2000, Censo de Población y Vivienda 2000, disponible en http:/www.inegi.gob.mx
} 
El Señor de la Expiración, también llamado el «Cristo Viajero»o «Cristo Peregrino», es una imagen de bulto que representa a Jesús en su cruz en el momento de morir, de ahí su nombre. La imagen reside en su santuario ubicado en la población de «Lo de Villa», que se conoce así porque se constituyó a partir de las tierras que a fines del siglo XVIII las autoridades de Colima otorgaron a las familias Biana y Villa:

Las autoridades de Colima en 1717 reconocieron [a] las familias Villa y Biana de origen español [...], les dieron algunas tierras laborables al poniente de la ciudad [...] a través del tiempo se ha conocido popularmente a esta propiedad como: Lo de Villa o perteneciente a la familia Villa $[\ldots]^{6}$.

Es importante mencionar que existen en el santuario tres imágenes del Señor de la Expiración: 1) la «peregrina», que es la reproducción que realiza las visitas; 2) la que llaman la «original» o el «Cristo quemado»; y 3) la imagen que se venera en el altar. Según Jesús Rodríguez Ruiz, cronista de Coquimatlán:

...el día 12 del mes de febrero 1938 a la media noche obedeciendo una orden del jefe de los agraristas de Coquimatlán, incendiaron el altar y las imágenes del Sr. de la Expiración y de la Virgen Dolorosa [...] aunque los vecinos creyeron que el incendio lo había ocasionado una veladora y estaban todos asombrados por tal suceso [...] las reliquias o restos de estas imágenes, todavía se veneran en el Santuario en un nicho adonde la gente acude a venerarlo como el Cristo quemado.

Ese mismo año el P. Bernardino Sevilla párroco de San Felipe de Jesús en Colima mandó hacer una imagen nueva a un escultor con ideas no tan ortodoxas, esta nueva imagen se bendijo el 28 de junio con gran solemnidad.

Este particular culto, como muchos otros, se ha ido construyendo a través de distintas narraciones que sustentan su carácter milagroso e histórico y por lo tanto legitiman y amplían la fe y la devoción. Se considera que la imagen del Señor de la Expiración llegó a Colima desde España en el siglo XVIII:

La familia Biana tenía entre sus parientes de España, un sacerdote [...que...], vio la necesidad de mandarles una imagen para que la veneraran y [...] mandó [...] la imagen del Cristo de la Expiración y la Virgen Dolorosa [...] los vecinos [...] pensaron luego hacer una pequeña capilla de adobe para albergar y venerar aquellas imágenes...?

\footnotetext{
6 Información recabada en la parroquia de Coquimatlán, Colima, enero 2005.
}

7 Información recabada en la parroquia de Coquimatlán, Colima, enero 2005 
Jesús Rodríguez Ruiz nos relató lo siguiente:

La imagen del Señor de la Expiración fue traída en el año de 1717, según ciertas personas, pero otras afirman que fue en 1729, pues en esta fecha fue terminada su primera capilla en la cual se le rendía culto.

El mismo cronista menciona que con el peregrinar de la imagen se puso fin a la sequía que siguió a una devastadora epidemia de fiebre amarilla de fines del siglo XIX:

En el año de 1884 Colima se ve terriblemente atacada por la fiebre amarilla que va extinguiendo muchas vidas, pero el pueblo que conoce la gran protección del Señor de la Expiración se acoge a él. Entonces se pide que se haga una réplica para que visite los lugares afectados por la fiebre y con su peregrinar llevar salud y vida a sus fieles devotos.

Los vecinos de Coquimatlán azotados por las sequías acordaron traer al Señor para pasearle por los sembradíos e implorarle las lluvias o también para agradecerle el buen temporal; estos movimientos tuvieron inicios en el año de 1884 y el sr. cura Manuel de la Concepción Ramírez, primer párroco de Coquimatlán, da fe de esta fecha en el escrito asentado en 1885 en el libro de gobierno de la parroquia de Coquimatlán.

También se le imploró por la salud de sus devotos en 1918, cuando se dio la influenza española.

Al Señor de la Expiración se le reconoce como un protector para aliviar problemas tales como sequías y epidemias; de manera que por esos motivos la milagrosa imagen ha salido en peregrinación desde finales del siglo XVIII y a partir de entonces se fijó como su día de culto el martes, ya que después de su primera salida regresó a su capilla un día martes, después de concluir el novenario correspondiente, es por eso que sus devotos acuden a su santuario los días martes para solicitar y agradecer favores. Hasta el momento no hemos encontrado información sobre este culto en el siglo XIX, pero según nos relatan los entrevistados, en el siglo XX durante el periodo cristero se redujo su fastuosidad; el cronista de Coquimatlán nos comentó al respecto:

Durante el tiempo de la persecución o la revolución cristera, se siguió la tradición, aunque con menos pompa [...] A través del tiempo la devoción popular ha ido creciendo [...] los exvotos y retablos que nos hablan de la religiosidad popular entendida a su modo y en su tiempo. 
A partir de 1947 el sacerdote Mateo Matías revitalizó el culto, organizando un recorrido de la imagen por las 13 poblaciones del municipio ${ }^{8}$ y otras aledañas. En cada lugar se realiza un novenario y una fiesta. El peregrinar anual de la imagen concluye con su traslado desde su última visita en la cabecera municipal de Coquimatlán hasta su santuario en Lo de Villa o Rancho de Villa el martes siguiente al 6 de enero. Ese día se suspenden las clases $^{9}$ y se pone una feria con comidas tradicionales y otras muchas mercancías agrícolas de consumo regional. También el cura Matías estableció la mayoría de las capillas en las 13 poblaciones del municipio, así como el recorrido en forma de cruz por las calles de la cabecera municipal en la noche anterior al regreso de la imagen a su templo.

A principios de los años 80 del siglo xx el padre Aguilar invitó a participar en la celebración patronal a los «hijos ausentes» y después la Sra. Olga Petrona solicitó la visita de la imagen durante dos meses a la ciudad de Los Ángeles en California, donde actualmente cuenta con una capilla y además visita las casas de sus devotos. Al regreso de la imagen el martes siguiente al 4 de julio se le recibe en el aeropuerto.

\section{LA CELEBRACIÓN EN EL AÑO 2005}

Actualmente la celebración es organizada por un patronato local y a ella acuden gran número de cuadrillas de danzas y pastorelas procedentes de todo el estado de Colima, así como de los estados de Jalisco y Michoacán. Muchos emigrantes aprovechan la ocasión para visitar a sus familias y para participar en la fiesta, lo que refuerza los lazos de parentesco consanguíneo y ritual, lo mismo que su cultura menoscabada por la migración. La fiesta patronal en «Lo de Villa» es la celebración más importante del año y se inicia con la llamada «entrada del Señor de la Expiración», que es el regreso de la imagen peregrina a su templo. La fecha es movible y corresponde al martes siguiente al día 6 de enero.

En la víspera, la noche anterior se realiza una velada que se describe localmente como festejo de gala al que se conoce como «recibimiento del Señor de la Expiración» y en el que, después de la misa, la imagen dentro de un

\footnotetext{
${ }^{8}$ De acuerdo con el cronista, son: Coquimatlán, Pueblo Juárez, Agua Santa, Algodonar, La Sidra, El Colomo, Cruz de Piedra, La Esperanza, El Chical, El Común, Los Limones, El Poblado y la Colonia Ejidal. En cada una hay una capilla donde se recibe a la imagen y los responsables de la visita son patronatos o «normas» integrados por 2 ó 3 personas.

${ }^{9}$ Gracias a un acuerdo con la SEP basado en el alto ausentismo escolar.
} 
nicho es transportada en un fastuoso carro alegórico. En el año 2005 la imagen se colocó en el centro del carro de aproximadamente $12 \times 4 \times 3$ metros (Esquema n. ${ }^{\circ} 1$ ), dentro de un ciprés coronado. En la decoración de este año, como de muchos otros, ha predominado el color dorado que las personas asocian con la santidad de la imagen y su providencia. En el año 2005 los encargados fueron los señores Anselmo Vargas, Florencio Méndez, Guadalupe Cruz Domínguez y Maximiliano Ruiz. Mientras se celebraba la misa en la plaza levantaban el castillo que sería quemado al terminar el recorrido, después de lo cual continuarían con «la velada» de la imagen las personas que la acompañarán al siguiente día hasta su santuario.

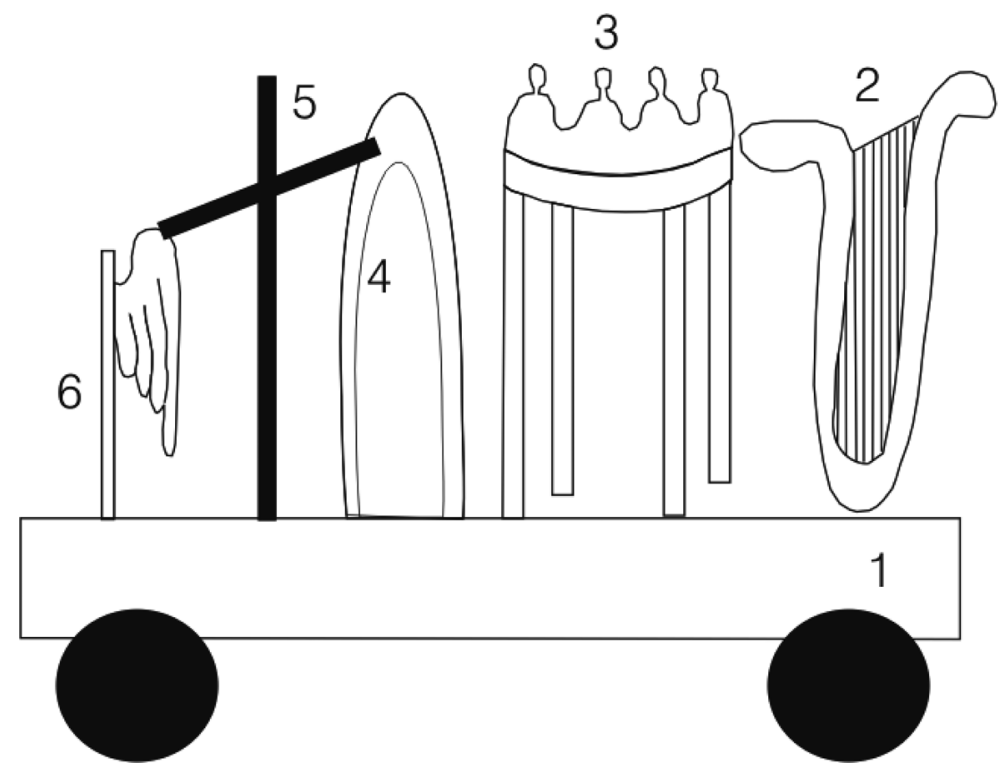

1. Carro

2. Lira

3. Ciprés coronado
4. Arco

5. Cruz

6. Estructura con alas para los ángeles

Esquema n. ${ }^{\circ}$ 1: El carro alegórico del 2005.

El día martes se celebró una misa como a las 5 de la mañana, después de la cual la imagen se colocó en el carro alegórico para dirigirse a Los Limones, que es el punto divisorio de las dos comunidades, la que entrega y la que recibe a la imagen, y donde se hace la entrega del Señor de la Expi- 
ración. El carro alegórico fue precedido de innumerables danzas, pastorelas, bandas y mariachi, además de ser resguardado por motocicletas de tránsito; detrás de la imagen caminaban cientos de peregrinos, a los que durante el recorrido se sumaron contingentes de todas partes del Estado y las personas que lo esperaban en Lo de Villa. El Sr. Cristóbal Rodríguez Álvarez, quien asiste año tras año en representación de la catedral de Colima «La Basílica menor», y que se encarga de «ir arreando a las danzas», nos comentó que el número varía según los años desde 12 hasta 40 danzas, pero que con el tiempo se han reducido «porque no les pagan los traslados». Una vez entregada la imagen, se le colocó en un anda que cargaban sobre vigas un gran número de hombres. Cabe mencionar que las personas de Coquimatlán han solicitado que se lleve en el carro alegórico hasta su templo, pero las personas de Lo de Villa se niegan. Al llegar a Rancho de Villa, aproximadamente a las 8 de la mañana, el sacerdote recibió a la imagen, rodeado de las danzas que la acompañan. La fiesta continúa con misas, un enorme mercado y presentación de las danzas en el atrio; a las 6 de la tarde se realiza un recorrido por las colonias.

Entre las danzas participantes podemos mencionar las de «Apaches», «Pastoras», «Yaquis», «Sonajeras», «Conquistas», «Malinche», «Conquistas Españolas», «Encostalados». En los grupos de danza, generalmente, quien toca el tambor es el maestro, el que enseña, ensaya, coordina y dirige al grupo. Las danzas hacen su presentación ante la imagen, formando filas para postrarse de uno en uno frente a la imagen, esto lo hacen tanto en la velada como al llegar al santuario. Los entrevistados comentaron que anteriormente asistían muchas cuadrillas de «los famosos pastores navideños», que dormían en el templo, pero, debido al temblor del 2003, ya no se puede por las obras de restauración del templo, por eso se ha reducido el número de cuadrillas.

\section{LOS «HIJOS AUSENTES»}

El número de emigrantes de Coquimatlán hacia los Estados Unidos para el trabajo agrícola se incrementó fundamentalmente a raíz del Programa Bracero, entre los años cuarenta y cincuenta del siglo XX, continuando hasta nuestros días; ahora con un alto número de indocumentados. Como una forma de mantener la participación de los llamados «hijos ausentes» en el culto católico y los vínculos con su lugar de origen, así como una manera de evitar las conversiones a otros credos, el padre Aguilar estableció, a partir de 
principios de los años ochenta del siglo $\mathrm{xx}$, las visitas de la imagen peregrina del milagroso Señor de la Expiración al vecino país del norte, con una duración de 2 meses, que concluyen el martes siguiente al 4 de julio. Para su visita al vecino país del norte, el Señor de la Expiración viaja en avión y a su regreso se le transporta en ancas (sobre caballos) desde el aeropuerto hasta su santuario, acompañado de muchos devotos.

Como sabemos, al emigrar las personas llevan consigo sus creencias, tradiciones y costumbres, su forma de vivir y de pensar, elementos con los que enfrentan «lo desconocido»y «lo peligroso» del lugar al que llegan. Los emigrantes también llevan a sus santos protectores que, generalmente, son los patronos de sus lugares de origen, o los santos reconocidamente milagrosos en sus regiones, además de otros de devoción más amplia como la Virgen de Guadalupe. Lo anterior se entiende al considerar que en la religiosidad popular, como menciona Jorge González (1994: 97-157), la relación con lo divino es inmediata y personalizada, por lo que la concepción y experiencia religiosa del pueblo, más que una función carismática para la salvación en el otro mundo, se hace cargo de todas las necesidades sociales, morales y psíquicas de los devotos; de manera que los creyentes piden a lo sagrado protección y ayuda ante los peligros que enfrentan y que, en el caso de los emigrantes ilegales a Estados Unidos, los riesgos pueden ser: la deportación, perderse durante el cruce de la frontera o sufrir cualquier percance.

\section{LOS S-CÓDIGOS DE LA DEVOCIÓN}

Los códigos a los que nos referiremos pueden ser descritos en términos de lo que Eco (1975 [1988: 153]) ha llamado s-códigos y que: 1) son sistemas o estructuras que pueden subsistir independientemente del propósito significativo o comunicativo que los asocie entre sí; 2) se componen de un conjunto finito de elementos estructurados en oposiciones y regidos por reglas combinatorias; 3 ) se postulan o reconocen precisamente para mostrar que los elementos de un sistema cultural pueden transmitir los elementos de otro subsistema; y 4) cuando se ven independientemente de otros sistemas pueden considerarse como estructuras que se elaboran en pares binarios, es decir, sistemas en los que los valores particulares se establecen mediante posiciones y diferencias que se revelan sólo cuando se comparan entre sí fenómenos diferentes mediante la referencia al mismo sistema de relaciones: bueno-malo, sagrado-profano. 
En nuestra investigación partimos de la hipótesis de que estos s-códigos se construyen históricamente y sirven como mecanismos comunicativos que coadyuvan a reforzar los lazos identitarios de los coquimatlenses, por lo que, de acuerdo a la definición de s-código, será necesario: 1) identificar los s-códigos de esta devoción como sistemas o estructuras significativas y comunicativas; 2) distinguir el conjunto de elementos que conforma cada uno de estos sistemas, así como sus oposiciones y reglas combinatorias; 3 ) mostrar la capacidad de elementos de los distintos sistemas para transmitirse de uno a otro; y 4) comparación con otros fenómenos a través de la referencia al mismo sistema de relaciones.

En esta ocasión presentamos los primeros avances de la investigación, por lo que sólo mencionaremos algunos de los s-códigos identificados durante nuestro trabajo de campo y que consideramos dan su especificidad a este culto. Según lo anterior, planteamos la comparación en dos niveles: a) espacial, en términos de otras devociones del calendario religioso local; y b) temporal, relacionado con los calendarios agrícolas locales ${ }^{10}$.

\begin{tabular}{|l|l|}
\hline \multicolumn{1}{|c|}{ S-código } & \multicolumn{1}{c|}{ Elementos } \\
\hline Espacio-temporal & $\begin{array}{l}\text { Territorio, reproducción de elementos iconográficos } \\
\text { en procesiones y relación del calendario festivo } \\
\text { religioso con el agrícola }\end{array}$ \\
\hline Corporal & El cuerpo físico devocional: danzas y postraciones. \\
\hline Identitario & $\begin{array}{l}\text { Imagen emigrante, cultura musical y dancística } \\
\text { (instrumentos, cantos, danzas } \\
\text { cultura alimentaria. Elementos expresados en cultura } \\
\text { local y de los migrantes. }\end{array}$ \\
\hline
\end{tabular}

En los elementos mencionados podemos correlacionar los siguientes planos:

10 Se tienen dos cosechas al año, la segunda se recoge en diciembre, poco antes de la celebración del Señor de la Expiración.

${ }^{11}$ Matachines, pastoras, danza azteca. 


\begin{tabular}{|c|c|c|}
\hline \multirow{2}{*}{ Elemento } & \multicolumn{2}{|r|}{ Planos } \\
\hline & Contenido & Expresión \\
\hline \multirow{3}{*}{$\begin{array}{l}\text { Coquimatlán } \\
\text { como espacio } \\
\text { y como } \\
\text { sistema } \\
\text { cultural }\end{array}$} & \multirow{3}{*}{$\begin{array}{l}\text { En Coquimatlán existe un } \\
\text { sistema cultural y devocional } \\
\text { particular reconocido como } \\
\text { «colimota». }\end{array}$} & $\begin{array}{l}\text { Existen capillas colimotas en cada } \\
\text { población del municipio y en Los } \\
\text { Ángeles, California. }\end{array}$ \\
\hline & & $\begin{array}{l}\text { En su recorrido la imagen visita todas las } \\
\text { capillas, incluida la de Estados Unidos. }\end{array}$ \\
\hline & & $\begin{array}{l}\text { En la vida diaria de los colimotas se } \\
\text { reproduce el sistema cultural y devocional, } \\
\text { sin importar su lugar de residencia. }\end{array}$ \\
\hline Iconográfico & $\begin{array}{l}\text { El Señor expiró } \\
\text { en una cruz. }\end{array}$ & $\begin{array}{l}\text { Las rutas de las procesiones nocturnas } \\
\text { conforman la figura de la cruz. }\end{array}$ \\
\hline \multirow{5}{*}{ Ofrendas } & \multirow{5}{*}{$\begin{array}{l}\text { Se dedican } \\
\text { a la imagen el } \\
\text { esfuerzo y la veneración. }\end{array}$} & Procesiones. \\
\hline & & Danzas. \\
\hline & & Postraciones. \\
\hline & & $\begin{array}{l}\text { Participación colectiva de la población } \\
\text { colimota. }\end{array}$ \\
\hline & & Carro alegórico. \\
\hline \multirow{2}{*}{$\begin{array}{l}\text { Imagen } \\
\text { itinerante }\end{array}$} & $\begin{array}{l}\text { El Señor de la Expiración } \\
\text { también es emigrante a } \\
\text { través de su imagen } \\
\text { peregrina. }\end{array}$ & $\begin{array}{l}\text { La imagen peregrina migra anualmente a } \\
\text { Los Ángeles (California). }\end{array}$ \\
\hline & $\begin{array}{l}\text { El Señor de la Expiración } \\
\text { protege a los coquimatlenses } \\
\text { tanto en su localidad como } \\
\text { fuera de ella. }\end{array}$ & $\begin{array}{l}\text { La imagen visita las casas de sus devotos } \\
\text { tanto en el municipio como en los Estados } \\
\text { Unidos. }\end{array}$ \\
\hline $\begin{array}{l}\text { Instrumentos } \\
\text { musicales }\end{array}$ & $\begin{array}{l}\text { Un elemento identitario } \\
\text { colimota es el arpa o lira } \\
\text { que distingue al mariachi } \\
\text { de Coquimatlán. }\end{array}$ & El carro alegórico incluye múltiples arpas. \\
\hline \multirow{2}{*}{$\begin{array}{l}\text { Coincidencia } \\
\text { de ciclos } \\
\text { de dos } \\
\text { subsistemas: } \\
\text { el agrícola y } \\
\text { el religioso }\end{array}$} & \multirow{2}{*}{$\begin{array}{l}\text { Coquimatlán } \\
\text { es un municipio } \\
\text { predominantemente } \\
\text { agrícola y católico }\end{array}$} & $\begin{array}{l}\text { Durante su ciclo festivo se le solicitan las } \\
\text { lluvias al Señor de la Expiración para el } \\
\text { éxito de las cosechas. }\end{array}$ \\
\hline & & $\begin{array}{l}\text { Se venera y agradece al Señor de la } \\
\text { Expiración por su intervención en las } \\
\text { actividades agrícolas. }\end{array}$ \\
\hline
\end{tabular}

${ }^{12}$ Asociaciones similares han sido descritas por Broda (1996) para los mexicas y por Ortiz (2004: 235-236) para el Señor de los Guerreros en el santuario del Tizonazo Durango. 
Sobre las postraciones, es necesario comentar que se realizan una vez que se retoma el recorrido, después de cada descanso, a los que se llama «posadas»; estas postraciones consisten en hincarse o tenderse sobre el camino empedrado, de manera que el anda o el nicho que transporta a la imagen pasa sobre las personas y éstas tienen que formar una larga fila; en particular, lo hacen los enfermos, quienes solicitan a un familiar o amigo que sea su «padrino de porrazo»y «los levante de la hincada». La solicitud de salud o de un favor de la persona se cumple gracias a la intervención del pariente consanguíneo o ritual.

En cuanto al carácter de emigrante de la imagen, cabe añadir que, a diferencia de muchos de sus devotos, el Señor de la Expiración viaja en avión y cuenta con un pasaporte que para los inmigrantes es un documento que, al igual que la Green Card, significa legitimidad y existencia como sujeto social en los Estados Unidos, tal como lo propusimos en otro trabajo (Ortiz, 2005: 233). La imagen es llevada en procesión de una cabalgata de equinos, portada por el abanderado en ancas (atrás de la silla) al aeropuerto y se recibe de regreso con mariachi en un ambiente festivo el martes siguiente al 4 de julio, fecha en que el país vecino celebra su independencia, día en que la imagen permanece en las localidades colimotas extraterritoriales con los trasterrados, a manera de potencia protectora, frente a la celebración del otro país.

\section{REFLEXIONES FINALES}

Las devociones, como la que se aborda en este trabajo, pueden estudiarse como procesos comunicativos, en los que los s-códigos se desarrollan y reformulan a través de la historia del culto del que se trate. Los elementos significativos, como son las visitas, las postraciones, las danzas, las peregrinaciones, la comida (pozole, coco en dulces y pan, recuerdo de naturaleza y de entorno productivo), los colores y otros, son propuestos y aceptados en el interior del grupo de organizadores y devotos, además de que, para el caso del Señor de la Expiración, los párrocos han desempeñado un importante papel.

El conocimiento del s-código es indispensable para poder acceder o leer el mensaje y entender la relación entre la procesión y la imagen venerada, el sentido de postrarse, danzar o recibir a la imagen en Estados Unidos. La competencia de «lector» se aprende de manera práctica al participar en el culto, y los distintos grados de participación determinan el que se conozcan 
desde los niveles más superficiales de significación hasta los más profundos e incluso se incida en los cambios que, a través del tiempo, ha tenido la devoción.

En el caso que analizamos están presentes elementos de diversos sistemas comunicativos de la cultura, además del religioso, como son los aspectos agrícolas y el de la migración. La perspectiva histórica nos permite contemplar este caso como un proceso creativo de construcción devocional e identitaria, en el que las inclusiones y cambios están relacionados con el contexto natural, social y político a nivel local, regional y más recientemente internacional.

Los cultos y sus s-códigos se construyen históricamente en la expresión de la cultura colimota tanto local como extraterritorialmente; en ellos, se sintetizan y expresan muchos de los valores y perspectivas de vida de los participantes, por lo que constituyen espacios privilegiados para el estudio de mecanismos comunicativos y significativos más allá del ámbito lingüístico.

\section{REFERENCIAS BIBLIOGRÁFICAS}

BRODA, J. (1996). «Calendarios, cosmovisión y observación de la naturaleza». En Temas mesoamericanos, Sonia Lombardo y Enrique Nalda (eds.), 427-469. México: INAH.

ECO, U. (1988). Tratado de semiótica general. México: Lumen.

GIMÉNEZ, G. (1978). Cultura popular y religión en el Anáhuac. México: Centro de Estudios Ecuménicos.

GONZÁLEZ, J. A. (1994). «Ex votos y retablitos. Comunicación y religión popular en México». En Más (+) cultura (s). Ensayos sobre realidades plurales, 97-157. México: CONACULTA (Colección Pensar la cultura).

GOOD E., C. (2005). «Ejes conceptuales entre los nahuas de Guerrero: expresión de un modelo fenomenológico mesoamericano». Estudios de Cultura Náhuatl (México: UNAM) 36, 87-113.

ORTIZ ECHÁNIZ, S. (2004). «Los pasaporteados de Dios. Peregrinos chihuahuenses al santuario del Señor de los guerreros en el Tizonazo Durango, en el norte de México». En IX Congreso de ALER: Religión y etnicidad. La religión en el nuevo milenio una mirada desde los Andes, tomo II, 231-242. Lima: Pontificia Universidad Católica del Perú. 
- (1995). «El proceso de elaboración de una identidad religiosa, el caso del espiritualismo trinitario mariano». En La identidad. Imaginación, recuerdos y olvidos, A. Pérez Castro (ed.), 19-28. México: UNAM, IIA.

ORTIZ ECHÁNIZ, S.; CORONA DE LA PEÑA, L. E. y VEGA FLORES, L. (2005). Diario de campo (manuscrito).

VEGA FLORES, L. (2005). «Entrevista al señor Pablo Ballesteros Silva», Coquimatlán, Colima, enero. 